\title{
Análise das dificuldades dos docentes relacionadas ao ensino de criança com Transtorno de Déficit de Atenção e Hiperatividade (TDAH)
}

Analysis of teachers 'dlifficulties related to teaching children with Attention and Hyperactivity Disorder (ADHD)

Análisis de las dificultades de los docentes relacionadas con la enseñanza de niños con Trastorno por Déficit de Atención con Hiperatomía e Hiperatividad (TDAH)

Ariella Sthefany Silva Oliveira ORCID: https://orcid.org/0000-0002-0123-3119 Centro Universitário UniFacid, Brasil E-mail: popyariella@gmail.com

Silvana Maria Véras Neves ORCID: https://orcid.org/0000-0003-4784-9135

Universidade de Fortaleza, Brasil

E-mail: silvanafisio7@yahoo.com.br

Luís Paulo Alves Ramos

ORCID: https://orcid.org/0000-0002-0196-8860

Universidade Federal de São Carlos, Brasil

E-mail: to.luispauloramos@gmail.com

Ivani Feitosa de Oliveira

ORCID: https://orcid.org/0000-0002-0662-8785 Universidade Federal do Piauí, Brasil

E-mail ivannioliveira@hotmail.com

Samyres Batista De Medeiros

ORCID https://orcid.org/0000-0001-5647-5783

Centro Universitário Uninovafapi, Brasil

E-mail: samyresmed28@gmail.com

Jaiane Oliveira Costa

ORCID https://orcid.org/0000-0003-3929-7334

Centro Universitário Unifacid Wyden, Brasil

E-mail: jaicostaenf@gmail.com

Rodrigo Feitosa de Oliveira Correia ORCID: https://orcid.org/0000-0002-8614-5555

Centro Universitário Unifacid Wyden, Brasil

E-mail: rodrigofeitosatsb@gamail.com

Walleska Suellen do Nascimento Silva ORCID: https://orcid.org/0000-0002-6696-3569

Centro Universitário Unifacid Wyden, Brasil E-mail walleskasuellen@gmail.com

Geovanna Mirella Palmer Lustosa ORCID: https://orcid.org/0000-0001-5402-7653

Centro Universitário Uninovafapi, Brasil E-mail: geolustosam@gmail.com

Pablo Henrique Doudement Lopes ORCID: https://orcid.org/0000-0003-1355-4806

Centro Universitário Uninovafapi, Brasil E-mail pablodoudemente@gmail.com 


\author{
Gabriela Dantas Carvalho \\ ORCID https://orcid.org/0000-0002-9571-3323 \\ Universidade Federal do Delta do Parnaíba, Brasil \\ E-mail: ftgabrieladantas@hotmail.com \\ Ana Flávia Machado de Carvalho \\ ORCID https://orcid.org/0000-0002-6691-4804 \\ Universidade Estadual da Paraíba, Brasil \\ E-mail: anaflaviaparaibana@ hotmail.com
}

\begin{abstract}
Resumo
O presente estudo teve como objetivo analisar as dificuldades dos docentes relacionados ao ensino de criança com TDAH. Tratou-se de uma pesquisa de campo, do tipo descritivo, com abordagem quali-quantitativa. Foi realizada a pesquisa através de um formulário online elaborado pela pesquisadora. A amostra foi composta por 8 professores de uma instituição de ensino privado da cidade de Teresina-PI, que lecionavam para crianças com TDAH no local da pesquisa. Como critério de inclusão, foram professores que lecionavam para alunos com TDAH há pelo menos um ano e aqueles que responderam à pesquisa no período de um mês. O instrumento de coleta de dados foi um formulário com questões objetivas, disponibilizado via internet pelo Google forms. Os resultados foram organizados no programa Microsoft Word em gráficos. Os resultados mostraram que 100\% dos docentes consideram ter dificuldade para atender crianças com TDAH, assim como necessitam de formação na área, pontuaram também em torno de 50\% que o aluno com TDAH interfere no rendimento da turma, tendo dificuldade em concluir as atividades escolares. Diante dos resultados, foi possível identificar o quanto é importante que os docentes sejam submetidos a capacitações prévias, para que possam se sentir aptos a trabalhar com a diversidade do público presente em sala de aula, visto que são fundamentais no desenvolvimento da criança no contexto escolar.
\end{abstract}

Palavras-chave: Formação docente; Inclusão escolar; TDAH.

\begin{abstract}
Attention Deficit Hyperactivity Disorder (ADHD) is characterized mainly by the lack of attention, the child is unable to stay focused on an activity for a long time, presenting difficulty in capturing various information, which implies impairment in his learning process. Teachers are the main collaborators in the child's development process in the school context, however, it can positively or negatively influence the life of students with ADHD, this influence being dependent on their training in the area. The present study aimed to analyze the difficulties of teachers related to the teaching of children with ADHD. It was a descriptive field research, with a qualitative and quantitative approach. The research was carried out through an online form prepared by the researcher. The sample consisted of 8 teachers from a private educational institution in the city of Teresina-PI, who taught children with ADHD at the research site. As an inclusion criterion, they were teachers who had been teaching students with ADHD for at least a year and those who responded to the survey within a month. The data collection instrument was a form with objective questions, made available via the internet through Google forms. The results were organized in the Microsoft Word program in graphics. The results showed that $100 \%$ of the teachers consider it difficult to care for children with ADHD, as well as they need training in the area, they also scored around 50\% that the student with ADHD interferes in the class performance, having difficulty in completing school activities. In view of the results, it was possible to identify how important it is for teachers to undergo previous training, so that they can feel able to work with the diversity of the audience present in the classroom, since they are fundamental in the child's development in the school context.
\end{abstract}

Keywords: Teacher training; School inclusion; ADHD.

\title{
Resumen
}

Este estudio tuvo como objetivo analizar las dificultades de los docentes relacionados con la enseñanza a niños con TDAH. Se trató de una investigación de campo descriptiva, con un enfoque cuali-cuantitativo. La investigación se realizó a través de un formulario online creado por el investigador. La muestra estuvo conformada por 8 profesores de una institución educativa privada de la ciudad de Teresina-PI, quienes enseñaron a niños con TDAH en el sitio de investigación. Los criterios de inclusión fueron profesores que habían estado enseñando a estudiantes con TDAH durante al menos un año y aquellos que habían respondido a la encuesta dentro de un mes. El instrumento de recolección de datos fue un formulario con preguntas objetivas, disponible a través de Internet mediante formularios de Google. Los resultados se organizaron en el programa Microsoft Word en gráficos. Los resultados mostraron que el $100 \%$ de los docentes consideran tener dificultad para atender a niños con TDAH, además de necesitar capacitación en el área, también puntuaron alrededor del 50\% que el estudiante con TDAH interfiere con el desempeño de la clase, teniendo dificultad para completar la escuela. actividades. A partir de los resultados se pudo identificar la importancia que tiene para los docentes la formación previa, para que se sientan capaces de trabajar con la diversidad del público presente en el aula, ya que son fundamentales en el desarrollo de los niños en el contexto escolar.

Palabras clave: Formación docente; Inclusión escolar; TDAH. 


\section{Introdução}

De acordo com Castro e Lima (2018), o Transtorno de Deficit de Atenção e Hiperatividade (TDAH) é caracterizado principalmente pela falta de atenção, onde os sintomas irão surgir durante a infância, geralmente antes dos 12 anos. Assim, a criança não consegue se manter focada em uma atividade por muito tempo, apresentando dificuldade para captar várias informações, o que implica no seu processo de aprendizado.

Assim, crianças com transtornos do desenvolvimento apresentam maior limitação na realização das suas atividades da vida cotidiana, na qual as dificuldades são vivenciadas diariamente pelas famílias. O comportamento atípico poderá acarretar perdas significativas no seu processo de desenvolvimento, principalmente no contexto escolar que será o local onde a criança desenvolverá inúmeras competências. Sendo assim, as instituições de ensino cumprem um papel muito importante na vida dessas crianças que possuem uma demanda escolar diferenciada (Martinhago, 2018).

Dessa forma, justifica-se a escolha do tema decorrente das dificuldades identificadas no processo de ensino de crianças com TDAH, necessitando assim de intervenções e formações que auxiliem os professores na elaboração de estratégias para inclusão escolar. A pesquisa apresenta assim, a importância da formação continuada, favorecendo os professores e, ao meio acadêmico e científico.

Foi elaborado como problema de pesquisa: quais são as principais dificuldades dos docentes relacionadas ao ensino de criança com TDAH?

O objetivo geral da pesquisa é identificar as principais dificuldades sob a óptica dos docentes, em relação ao processo de ensino de crianças com TDAH. Para que tal objetivo fosse alcançado, fez-se necessário atingir três objetivos específicos: avaliar junto aos docentes as formações realizadas previamente para preparo do ensino com crianças TDAH; verificar as dificuldades dos docentes no ensino de crianças com TDAH e; detectar a necessidade de formação continuada dos docentes para trabalhar com alunos que possuem dificuldades no âmbito escolar.

\section{Metodologia}

A elaboração do presente projeto obedece à resolução no 466/12 do Conselho Nacional de Saúde (CNS), que delineia as diretrizes éticas e normas regulamentadoras da pesquisa com seres humanos. Assim, mediante autorização da instituição em que ocorreu a pesquisa, e submissão via Plataforma Brasil ao Comitê de Ética em Pesquisa (CEP) do Centro Universitário UniFacid, deu-se início a mesma. Foi solicitada a assinatura do Termo de Consentimento Livre e Esclarecido (TCLE), assegurando o anonimato e o sigilo das informações dos participantes, na qual estavam cientes dos riscos, benefícios, procedimentos e objetivos da pesquisa.

Tratou-se de uma pesquisa de campo, do tipo quali-quantitativa descritiva, na qual foram analisadas as dificuldades dos docentes relacionadas ao ensino de criança com TDAH.

Esta pesquisa foi realizada na cidade de Teresina-PI, no mês de agosto do ano de 2020, através um formulário online disponibilizado pelo Google forms via endereço eletrônico, onde a amostra foi composta por 8 professores de uma instituição de ensino privado. Como critério de inclusão para pesquisa, foram professores que trabalham com alunos com TDAH na escola em estudo há pelo menos um ano e aqueles que responderem à pesquisa no período de um mês, sendo todos os formulários emitidos no mesmo dia para todos os participantes. Os critérios de exclusão foram professores substitutos, que estivessem exercendo o cargo apenas temporariamente nas salas de aula selecionadas e aqueles que não respondessem à pesquisa no período que determinado pela pesquisadora.

Após a coleta de dados, os mesmos foram transcritos e submetidos à análise do conteúdo, e posteriormente organizados em gráficos do programa Microsoft Excel.

A pesquisa não ocasionou riscos aos participantes que foram entrevistados, levando apenas a um leve desconforto 
pelo tempo gasto para responder o questionário enviado via online que analisou as dificuldades dos docentes para atender crianças com TDAH, sendo disponibilizado pelo pesquisador e respondido individualmente por cada participante no período de um mês. No entanto, caso ocorresse algum desconforto ou constrangimento, os participantes seriam encaminhados a um serviço de psicologia gratuito via internet, ficando à vontade para suspender a pesquisa em qualquer momento, sem nem um custo ou prejuízo.

A pesquisa ajudou no fornecimento de dados atuais sobre o processo de ensino- aprendizagem de alunos com TDAH, que poderá ajudar a desenvolver estratégias que auxiliem o professor em sala de aula.

\section{Resultados e Discussão}

O Gráfico 1 apresenta a quantidade de docentes que encontram dificuldades na sala de aula para trabalhar com crianças diagnosticadas com TDAH, dos 8 participantes, 5 participantes $(62,50 \%)$ sinalizaram ter dificuldade apenas com pouca frequência.

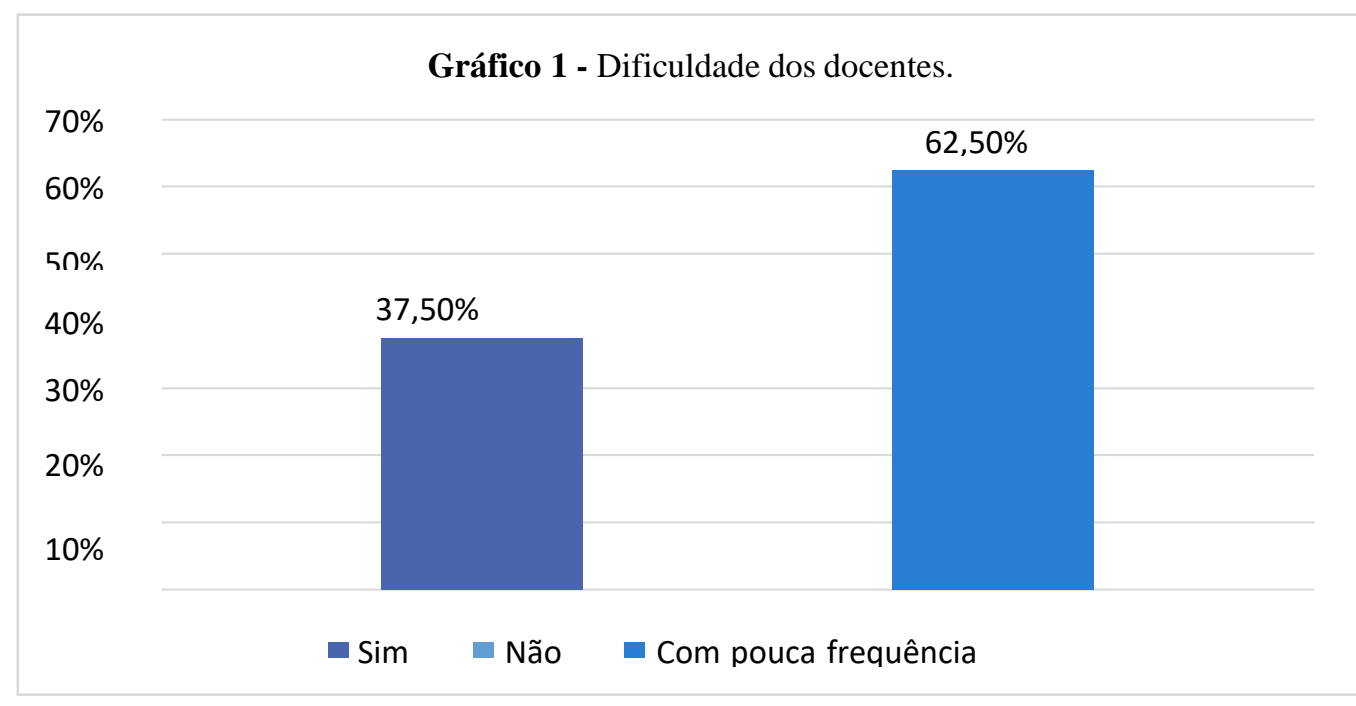

Fonte: Autores (2021).

Foi uniforme a todos os docentes desta pesquisa a percepção das dificuldades para executar suas atividades escolares com crianças TDAH. Semelhante ao estudo realizado na Argentina e no México com 48 professores, que teve como objetivo comparar o conhecimento e as atitudes de professores da educação básica em relação a alunos com TDAH nesses dois países. Os professores demonstraram um nível de conhecimento que varia de suficiente a baixo. Para a avaliação de atitudes e crenças, os resultados mostram que apenas 50\% e $60 \%$ dos professores possuem crenças e atitudes desfavoráveis em relação aos alunos com TDAH. Foi concluído que esses resultados ocasionam dificuldades para lidar com o transtorno, devido à falta de conhecimento e estratégias para responder adequadamente às necessidades desses alunos (Monsivais; Herrera, 2020).

O estudo que consistiu em apresentar as dificuldades e barreiras encontradas pelos docentes de um colégio estadual, em um município do Estado do Paraná, em relação ao processo de ensino e aprendizagem de alunos que possuem algum distúrbio de aprendizado, principalmente do TDAH, apresentou nos resultados que os professores têm pouco conhecimento nessa área e têm dificuldades para lidar com estes alunos, estando a maioria relacionadas com a falta de recursos que os mesmos possuem e a superlotação das salas de aula, sendo ressaltado que esses alunos precisam de uma atenção individual, e que muitas vezes necessitam aprender de maneira mais lúdica e diferenciada (Santos; Takahashi; Oliveira, 2020). Concordante com o achado deste, permitindo destacar os fatores que podem estar relacionados com as dificuldades dos professores para 
atender crianças com TDAH.

O Gráfico 2 apresenta dados sobre a realização de atividades repassadas na sala de aula de maneira satisfatória por alunos com TDAH, sob a ótica dos professores, metade da amostra (50\%) relataram que sim e a outra metade (50\%) que não.

\section{Gráfico 2 -}

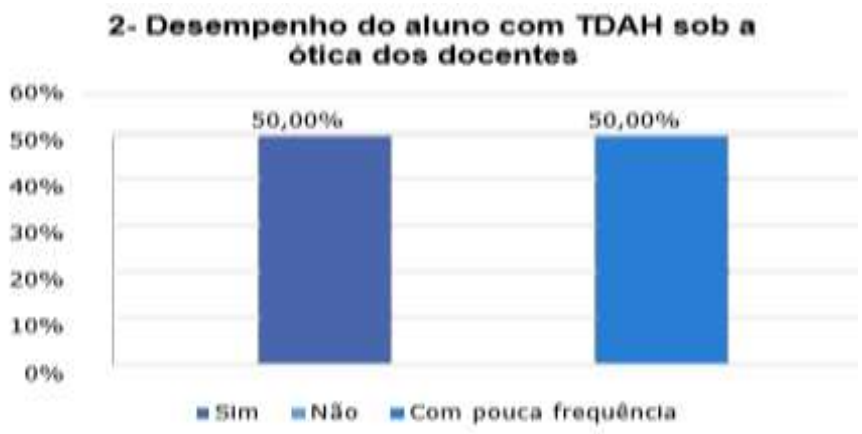

Fonte: Autores (2021).

O Araújo (2020) em seu estudo teve como objetivo identificar e descrever quais são os possíveis fatores associados ao mau desempenho escolar de crianças com TDAH, apontou nos resultados déficits cognitivos, psicomotores, comorbidades, algumas características do próprio ambiente escolar e relações familiares fragilizadas, como fatores principais associados ao insucesso escolar dos educandos que tem o transtorno.

Um estudo desenvolvido sobre a análise de desempenho escolar e planejamento motor de uma criança com e outra sem TDAH, evidenciaram um desempenho inferior da criança com TDAH quando comparada à criança sem o transtorno no desempenho escolar, e no engajamento motor durante as aulas de Educação Física, portanto, para que ocorram mudanças positivas, as atividades precisam ser interessantes e estimulantes a todos os alunos, principalmente aos alunos que possuem dificuldades de atenção e baixo engajamento na atividade proposta (Américo; Kappel; Berleze, 2016). Os achados dos estudos citados reforçam os resultados desta pesquisa.

No Gráfico 3, é possível identificar como os docentes consideram ter uma criança com TDAH na sala de aula, relacionando com a interferência no rendimento da turma, $62,50 \%$, relataram que interfere com pouca frequência.

\section{Gráfico 3 -}

\section{3- Interferência do aluno com TDAH sob a ótica dos docentes}

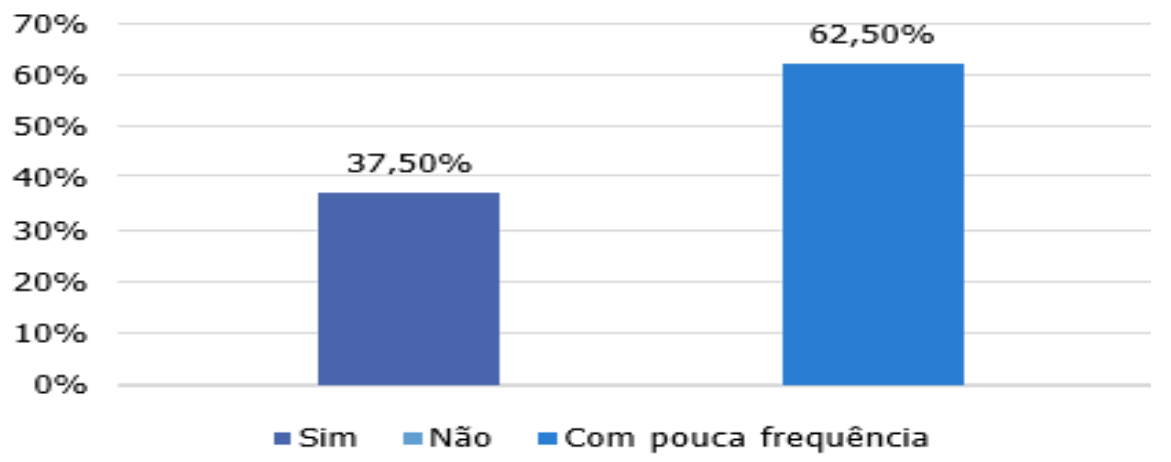

Fonte: Autores (2021).

A pesquisa de Martinhago e Caponi (2019) vai de acordo com os dados do presente estudo, a mesma foi realizada 
com 15 profissionais de uma escola, sendo destes 13 professores, incluindo 1 diretor e 1 coordenadora pedagógica, tendo como objetivo analisar as estratégias dos professores para a identificação e intervenção mediante comportamentos que indicam o diagnóstico de TDAH e, de acordo com os resultados os professores relataram que essas crianças afetam a dinâmica em sala de aula, visto que, pelas suas dificuldades de concentração atrapalham toda a turma.

Outro estudo que teve como objetivo compreender os impactos no que tange o rendimento escolar de estudantes com e sem NEE inseridos em uma mesma classe do ensino comum, em comparativo a outras classes que não possuem estudantes inclusos com NEE nos anos finais do ensino fundamental, apresenta nos resultados que a classe que possui estes estudantes com NEE obteve um rendimento escolar na média como as demais classes (Pereira, 2017). Discordantes com o achado deste estudo, no qual $100 \%$ dos participantes relataram que o aluno com TDAH interfere no rendimento da turma.

Com relação aos docentes que se sentem aptos e capacitados para atender alunos com TDAH, 5 dos participantes $(62,50 \%)$ relataram que sim, dados demonstrados no (Gráfico 4).

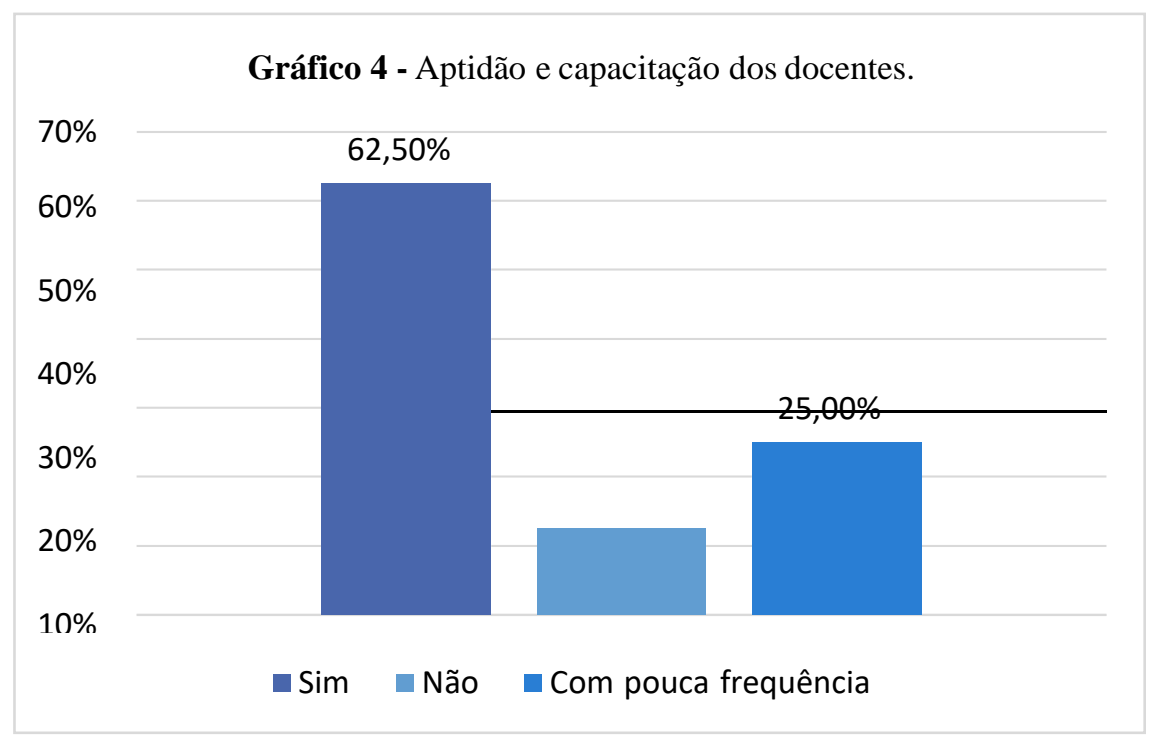

Fonte: Autores (2021).

Reforçando os achados deste estudo, Freitas (2017), em seu estudo realizado com 5 professores que atuam nos anos iniciais, tendo como objetivo identificar a formação do professor como eixo de inclusão no desenvolvimento da aprendizagem dos alunos com deficiência, apresentou nos resultados, que apenas 1 professora possui especialização em Educação Especial, sendo este fator fundamental para o desempenho das suas atividades em sala de aula, e os demais (4 participantes) relataram sentir muita dificuldade e insegurança para trabalhar com alunos com deficiência.

De acordo com a literatura, muitas vezes os professores se sentem despreparados e incapacitados para atender aluno com NEE, devido o grande número de alunos por sala, a falta de materiais adequados e a ausência, muitas vezes, de um profissional do Atendimento Educacional Especializado (AEE) para auxiliar os professores adequadamente, principalmente àqueles que não passaram por quaisquer formações na área da educação especial (Lima; Jerônimo; Gouveia, 2020). Alguns apontam ainda as questões metodológicas como principal barreira na prática de ensino (Silva et al., 2017).

O Gráfico 5 apresenta a quantidade de docentes que foram capacitados para atender crianças com TDAH, dos quais 6 participantes $(75 \%)$ responderam ter formação na área. 


\section{Gráfico 5 -}

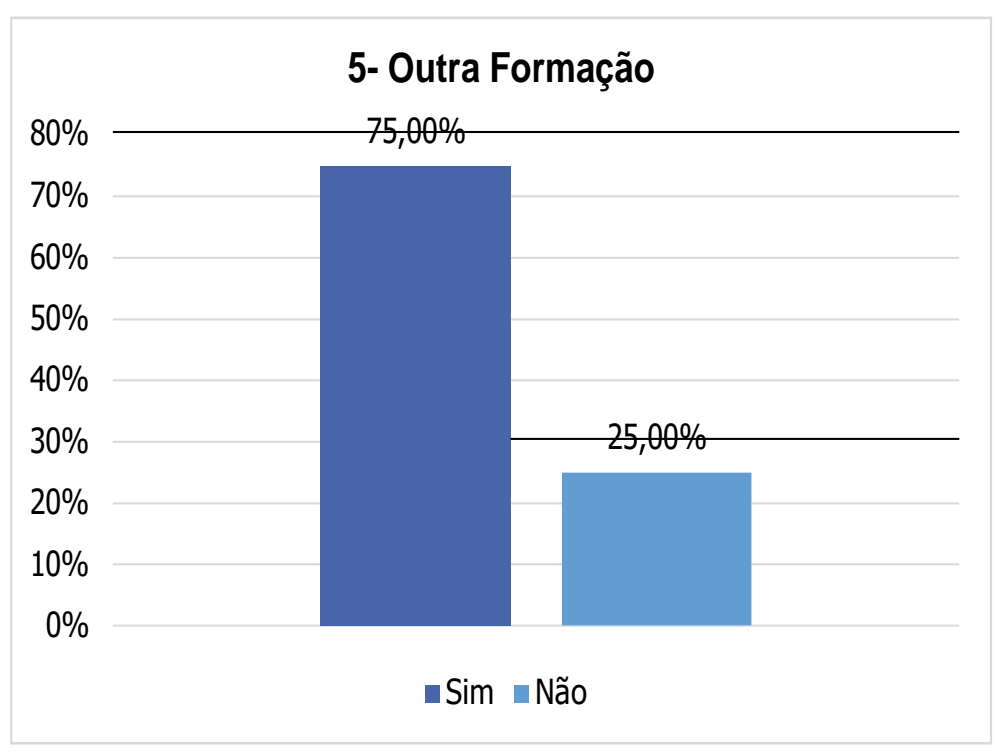

Fonte: Autores (2021).

Uma pesquisa realizada com 50 docentes voluntários que lecionam no primeiro ciclo do Ensino Fundamental de Sousa, Barros e Diascânio (2020), sobre a adaptação nas metodologias de ensino nas salas de aula para atender as demandas educacionais de alunos com TDAH, apresentou nos seus resultados que, os professores foram indagados se receberam alguma capacitação para trabalhar com crianças com TDAH, a maioria dos voluntários $(92 \%)$ respondeu que não possui cursos ou capacitação. Discordante dos achados deste estudo, no qual a maioria (6 participantes) relataram que possuem formação continuada, sendo esse fator importantíssimo para que o professor consiga atender as demandas diferenciadas presentes na sala de aula.

Outro estudo realizado com 42 professores do ensino fundamental que frequentam escolas públicas, localizadas em áreas rurais e urbanas do Uruguai, na qual todos lecionavam direto no quinto e sexto ano na área de Educação Comum, teve como objetivo conhecer a atitude dos professores da rede pública de ensino em relação aos seus alunos com deficiência. De acordo com os resultados apenas 9,5\% dos participantes fizeram cursos na área da educação especial e referiram dificuldades no processo de ensino e aprendizagem (Bermudez; Antola, 2020)

Fica evidente com os achados dos estudos acima citados e resultados encontrados neste, que para os que não possuem formação para trabalhar com esse público, torna-se imprescindível repensar e buscar alternativas que o auxiliem no processo de aprendizagem de acordo com as características de cada aluno, através de capacitações que possam abranger vários tipos de NEE (Carvalho et al., 2020).

Os docentes consideram que necessitam de formação realizada previamente para atender crianças com TDAH, 100\% da amostra relataram que sim, representados no Gráfico 6. 


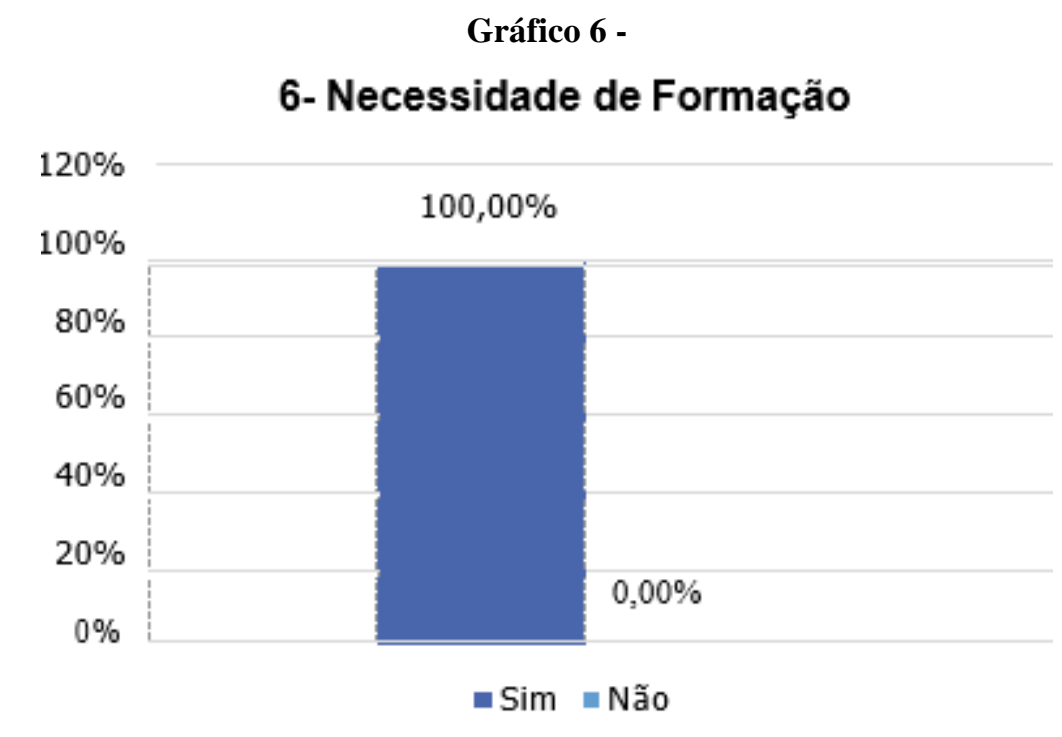

Fonte: Autores (2021).

Tavares, Santos e Freitas (2016), entrevistaram 52 professores, com intuito de investigar a formação em educação inclusiva de professores da rede pública que atuam com crianças com deficiência, em escolas regulares do ensino fundamental. Como resultado, os professores reconhecem a importância da formação continuada e sentem angústia pela percepção da formação docente insuficiente, pois necessitam de buscas por capacitações para preencher essa lacuna, para só assim ser possível trabalhar e incluir de fato crianças com algum transtorno ou deficiências.

O estudo realizado com 19 professores da rede pública municipal de ensino do Município de Pelotas/RS aponta nos resultados, que a falta de preparo na formação inicial, foi um ponto levantado por 16 professoras, na qual a ausência de disciplinas, cursos, materiais e informações específicas influenciam no sentimento de despreparo frente à sua prática com alunos com transtornos globais do desenvolvimento, necessitando assim de formação realizada previamente (Camargo et al., 2020).

Esses dados enfatizam os resultados da presente pesquisa, pois 100\% dos participantes consideram a importância da formação continuada, e por mais que alguns professores possuam capacitações para trabalhar com a diversidade do público presente em sala de aula, ainda assim demonstram a necessidade desta formação continuada, sentindo a necessidade diante da deficiência como docente, de buscar estratégias que facilitem o processo de inclusão.

O Gráfico 7 mostra os dados referentes ao suporte da escola para atuação do docente em sala de aula na inclusão, evidenciando que os 8 participantes (100\%) sinalizaram que sim. 


\section{Gráfico 7 -}

\section{7-Ajuda da Escola}

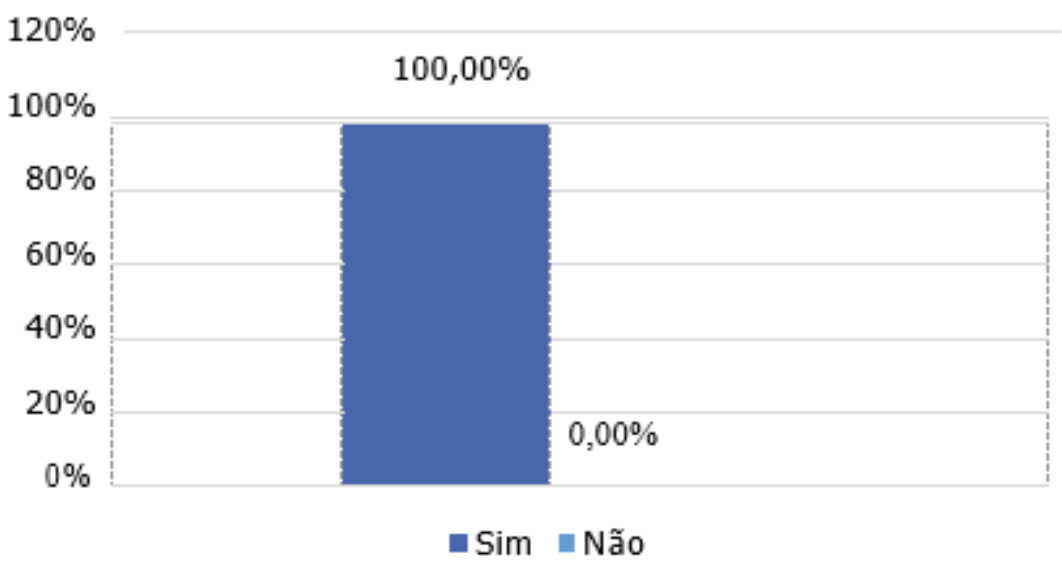

Fonte: Autores (2021).

A pesquisa realizada em três escolas de Ensino Fundamental de $1 .^{\mathrm{a}}$ a $4 .^{\mathrm{a}}$ série (uma municipal, uma estadual e outra privada), que consideram adotar a educação inclusiva, tendo como participantes 3 professoras indicadas pela diretoria de cada uma das escolas, objetivou identificar fatores considerados necessários para a implementação da educação inclusiva ligados aos professores e sua atuação, apresentou como resultado que, 1 professora comentou que na escola existe participação dos professores no planejamento pedagógico, mas não há nada específico sobre a educação inclusiva, surgindo dificuldade no estabelecimento de relações democráticas entre a escola e os professores (Dias; Rosa; Andrade, 2015).

O estudo realizado com 6 professoras, seus alunos com NEEs e 3 profissionais do Núcleo de Educação Inclusiva da Secretaria Municipal de Educação, que teve como objetivo, analisar as demandas dos professores decorrentes da inclusão escolar, indicando nos resultados que existem conquistas e contradições nas escolas que se propõem inclusivas, tendo avanços e limitações resultantes da política municipal, e que o modelo de atuação da equipe de educação especial no contexto analisado pode ser revisto ou ampliado (Matos; Mendes, 2015). Esses achados são discordantes do presente estudo, visto que dos participantes consideram que a escola oferece suporte para sua atuação docente em sala de aula na inclusão, este achado pode ter ocorrido devido ao fato da pesquisa ter sido realizada em uma instituição de ensino privada, podendo ter deixado o professor com receio de relatar a realidade em uma instituição de ensino privada, podendo ter deixado o professor com receio de relatar a realidade.

\section{Conclusão}

Conclui-se que os docentes encontram dificuldades para exercer a docência com crianças TDAH, quando inseridas na escola regular, ocasionando assim muitas vezes um desempenho insatisfatório desse aluno nas atividades propostas, que leva a reflexão, se esta advém só pela dificuldade pertinente da clientela ou da falta de preparo e estratégias do professor.

Evidenciando nos achados, a inerente necessidade das capacitações prévias para atender a diversidade do público em sala de aula, sendo eixo fundamental no desenvolvimento da criança no contexto escolar, visto que permite enxergar as potencialidades personalizadas de cada um, e traçar estratégias, apesar de todas as dificuldades inerentes ao transtorno.

\section{Referências}

Américo, C. D. P., Kappel, N. R. R., \& Berleze, A. (2016). A criança com TDAH: análise do desempenho escolar e engajamento motor. Cinergis, 17(2), 150156. 
Research, Society and Development, v. 10, n. 13, e120101320678, 2021

(CC BY 4.0) | ISSN 2525-3409 | DOI: http://dx.doi.org/10.33448/rsd-v10i13.20678

Araújo, R. S. (2020). Fatores associados ao mau desempenho escolar de crianças com Transtorno do Déficit de Atenção e Hiperatividade. Revista Saúde.comCiência, (1), 31-42.

Bermudez, M. M., \& Antola, I. N. (2020). Atitudes dos professores diante da inclusão de alunos com deficiência. Cienc. Psicol., Montevideo, 14(1).

Camargo, S. P. H. et al. (2020). Desafios no processo de escolarização de crianças com autismo no contexto inclusivo: diretrizes para formação continuada na perspectiva dos professores. Educ. rev., 36.

Carvalho. et al. (2020). Transtorno do Déficit de Atenção com Hiperatividade (TDAH) e seus desafios no ambiente escolar: pesquisa de campo na emef manoel vieira lessa, em serra - es. Conhecimento em Destaque.

Castro, C. X. L, \& Lima, R. F. (2018). Consequências do transtorno do déficit de atenção e hiperatividade (TDAH) na idade adulta. Rev. Psicopedagogia, 35(106): 61-72.

Dias, M. A. L., Rosa, S. C., \& Andrade, P. F. (2015). Os professores e a educação nclusiva: identificação dos fatores necessários à sua implementação. Psicologia USP, 6(3),453- 463.

Freitas, L. J. (2017). A Formação do professor como eixo inovador de inclusão no ensino fundamental dos alunos com deficiência em Limoeiro/Pernambuco. Rev. Int. Investig. Cienc. Soc., Asunción, 13(2), 225-238.

Lima, F. C., Jerônimo, R. C. G. F., \& Gouveia, L. F. P. (2020) Educação inclusiva: os desafios da formação e as dificuldades na atuação docente. Braz. J. of Develop. 6(10), 79580-79591.

Martinhago, F. (2018). TDAH e Ritalina: neuronarrativas em uma comunidade virtual da Rede Social Facebook. Ciência e Saúde Coletiva. $23(10): 3327-3336$.

Martinhago, F., \& Caponi, S. (2019). TDAH Em Crianças E Adolescentes: Estudo Com Professores Em Uma Escola Pública Do Sul Do Brasil. Cadernos Brasileiros de Saúde Mental, 11(30), 78-98.

Matos, S. N., \& Mendes, E. G. (2015). Demandas de professores decorrentes da inclusão escolar. Rev. Bras. Ed. Esp., 21(1), 9-22.

Monsivais, J. M., Herrera, A. D. R. C. (2020) Comparação de conhecimentos e atitudes de professores do ensino fundamental em relação a alunos com transtorno de déficit de atenção e hiperatividade e TDAH na Argentina e no México. Rev. study. exp. educ. 19(40).

Pereira, E. D. (2017). Um estudo sobre os impactos da inclusão no rendimento escolar. Educere- XII Congresso nacional de educação.

Santos, M. S. B., Takahashi, B. T., \& Oliveira, A. L. (2020). Dificuldades encontradas pelos docentes de uma escola estadual localizada no estado do paraná frente a alunos que apresentam distúrbios de aprendizagem. RECH- Revista Ensino de Ciências e Humanidades - Cidadania, Diversidade e Bem Estar. Ano 4, 6(1),45-67.

Silva. et al. (2017) Materiais Didáticos inclusivos para o Ensino de Química: desafiando professores em formação. XI Encontro Nacional de Pesquisa em Educação em Ciências - XI ENPEC Universidade Federal de Santa Catarina, Florianópolis, SC.

Sousa. L. P. A., Barros, L. A., \& Discânio, J. M. (2020) Adaptações na metodologia de ensino para atender as demandas educacionais de alunos com tdah. Brazilian Journal of Development. 6(1), 370-378.

Tavares, L. M. F. L., Santos, L. M. M., \& Freitas, M. N. C. (2016) A Educação Inclusiva: um Estudo sobre a Formação Docente. Rev. Bras. Ed. Esp., 22(4), $527-542$. 